\title{
Pengaruh Latihan Dribbling With A Curving Line Trajectory Untuk Meningkatkan Keterampilan Dribbling Pemain Sepak Bola Ps. Undikam Mataram Tahun 2019
}

\author{
Ismail Marzuki ${ }^{1}$, Soemardiawan ${ }^{2}$ \\ ${ }^{1,2}$ Fakultas Ilmu Keolahragaan Dan Kesehatan Masyarakat, UNDIKMA \\ ismailmarzuki@ikipmataram.ac.id, umanksoemardiawan84@gmail.com
}

\begin{abstract}
The focus of the problem in this research When competing frequently there are mistakes in dribbling, so from this it is necessary to have this exercise, to improve the dribbling skills of PS players. UNDIKMA Mataram. The purpose of this study is to determine whether there is an effect of Dribbling With A Curving Line Trajectory Exercise on the Dribbling Skills of PS Soccer Players. Mataram UNDIKMA 2019 ". The research methods used by researchers are the observation method, the documentation method and the deed test method. The study design uses a pretest-posttest design (initial test and final test). The population used in this study are all PS players. UNDIKMA Mataram in 2019. The number of samples in the study conducted was 22 which became a sample of 11 players PS soccer players. UNDIKMA Mataram. The sampling technique in this study using the saturation sampling technique is a sampling technique if all members of the population can be sampled. Analysis of statistical data with a significance level of 5\% for the speed test results obtained by the tvalue so from the results of research X1 (Dribbling With A Curving Line Trajectory, with Y1 obtained tcount is much greater than ttable, this shows that the hypothesis "Ha" (accepted) then this research is significant, drawing conclusions from the table analysis at a significant level of $5 \%$ with a number of samples $(\mathrm{n}-1)$ that is $11-1=10$ at 1,812 . Then it can be concluded that, 1) The Effect of Dribbling With A Curving Line Trajectory on Dribbling Skills PS Football Players. Mataram UNDIKMA 2019, Tcount> ttable (7.362> 1,812). 2). this shows that the hypothesis "Ha" (accepted) then this research is significant.
\end{abstract}

Keywords: Training, Skills, Dribbling With A Curving Line Trajectory, Football

Abstrak. Fokus masalah dalam penelitian ini Pada saat bertanding sering terjadinya ke salahan dalam melakukan dribbling, maka dari hal tersebut perlu adanya latihan tersebut, ini untuk meningkatkan keterampilan dribbling pada pemain PS. UNDIKMA Mataram.Tujuan penelitian ini adalah Untuk Mengetahui Apakah Ada Pengaruh Latihan Dribbling With A Curving Line Trajectory Terhadap Keterampilan Dribbling Pemain Sepak Bola PS. UNDIKMA Mataram Tahun 2019”. Metode penelitian yang digunakan peneliti yaitu metode observasi, metode dokumentasi dan metode tes perbuatan. Rancangan penelitian menggunakan pretest-posttest design (tes awal dan tes akhir). Populasi yang digunakan dalam penelitian ini yaitu keseluruhan pemain PS. UNDIKMA Mataram tahun 2019. Jumlah sampel pada penelitian yang dilakukan adalah 22 yang menjadi sampel sebanyak 11 orang pemain orang pemain sepak bola PS. UNDIKMA Mataram. Teknik penarikan sampel dalam penelitian ini menggunakan teknik sampling jenuh adalah teknik penentuan sampel bila semua anggota populasi bisa dijadikan sampel. Analisa data statistik dengan taraf signifikan 5\% untuk hasil tes kecepatan diperoleh nilai t-hitung Jadi dari hasil penelitian X1 (Dribbling With A Curving Line Trajectory, dengan $\mathrm{Y} 1$ diperoleh $\mathrm{t}_{\text {hitung }}$ jauh lebih besar dari $\mathrm{t}_{\text {tabel }}$, hal ini menunjukkan bahwa hipotesis "Ha" (diterima) maka penelitian ini signifikan. menarik kesimpulan analisis tabel pada taraf signifikan 5\% dengan jumlah sampel $(\mathrm{n}-1)$ yaitu 11-1 = 10 sebesar 1.812. Maka dapat disimpulkan bahwa, 1) Pengaruh Latihan Dribbling With A Curving Line Trajectory Terhadap Kterampilan Dribbling Pemain 
Sepak Bola PS. UNDIKMA Mataram Tahun 2019, Nilai $\left.t_{\text {hitung }}>t_{\text {tabel }}(7,362>1.812) .2\right)$. hal ini menunjukkan bahwa hipotesis "Ha" (diterima) maka penelitian ini signifikan.

\section{Kata Kunci: Latihan, Keterampilan, Dribbling With A Curving Line Trajectory, Sepakbola}

\section{PENDAHULUAN}

Permainan sepakbola merupakan salah satu cabang olahraga yang paling populer di dunia dan digemari oleh seluruh masyarakat dari tingkat anak-anak, tua, muda, pelajar, mahasiswa dan lapisan masyarakat lainnya. Hal ini dapat dilihat dari animo masyarakat dalam menyaksikan World Cup, Liga Champion $U E F A$, dan pertandingan international daripada menyaksikan pertandingan olahraga yang lain. Gerakan pemain yang bebas dan terkontrol mengekspresikan individualitas dalam permainan beregu, kecepatan, kekuatan, stamina, keterampilan, dan pengetahuan mengenai tehnik dan taktik semacamnya merupakan aspek yang penting dari permainan sepakbola. Kepopularitasan olahraga ini tidak perlu diragukan lagi. Karena cabang olahraga sepakbola merupakan cabang olahraga yang sering dipertandingkan di event-event resmi baik tingkat nasional maupun internasional.

Sepakbola merupakan permainan beregu, yang masing-masing regunya terdiri dari 11 pemain yang salah satunya sebagai penjaga gawang. Permainan ini hampir seluruhnya dimainkan dengan menggunakan seluruh anggota badan kecuali penjaga gawang boleh menggunakan kedua tangannya, namun di daerah gawang). Perkembangan sepakbola di Indonesia sangat baik khususnya Nusa Tenggara Barat, namun belum bisa diikuti dengan prestasi tingkat nasional maupun internasional, hal ini disebabkan karna beberapa faktor, yaitu: faktor teknik, faktor taktik, faktor fisik, dan faktor yang paling mendasar yaitu faktor pendanaan, perwasitan dan kurangnya pelatih profesional. Hendaknya faktor di atas perlu diperhatikan oleh pengurus sepakbola, pemain, pelatih, pemerintah atau instansiinstansi yang terkait sehingga tercipta prestasi maksimal.
Dari hasil pengamatan dilapangan banyak pemain yang mempunyai kelincahan pada saat menggiring bola, tetapi kesimbangan mempertahankan bola kurang sehingga pemain tersebut sering terjatuh, begitu juga sebaliknya apabila mempunyai keseimbangan yang bagus tetapi tidak mempunyai kelincahan, maka saat menggiring bola terlihat lambat. Menggiring bola bertujuan untuk mendekati jarak sasaran, melewati lawan, memperlambat tempo permainan, memindahkan bola didaerah permainan, dan memancing lawan untuk mendekati bola hingga daerah penyerangan terbuka. Untuk menunjang keberhasilan mencapai teknik tersebut sangat dibutuhkan kecepatan dalam menggiring bola. Untuk mencapai teknik kecepatan menggiring bola harus didukung oleh kondisi fisik yang baik. Dengan penguasaan teknik, psikologis dan kondisi fisik yang baik maka seseorang akan lebih mudah mencapai prestasi yang maksimal. Berbagai bentuk latihan untuk meningkatkan dribbling seperti: Dribbling with a curving line trajectory model latihan ini ada dugaan sangat berpengaruh terhadap hasil kecepatan menggiring bola.

Maka fokus masalah yang dihadapi, serta dari itu atas dasar keperihatinan akan mandeknya prestasi sepakbola Indonesia pada umumnya dan daerah kita pada khususnya (Nusa Tenggara Barat) dan keinginan untuk mengembangkan bakat-bakat para pemain di kalangan Mahasiswa, maka di dirikanlah PS. UNDIKMA Mataram". Pada saat bertanding sering terjadinya ke salahan dalam melakukan dribbling, maka dari hal tersebut perlu adanya latihan dribbling with a curving line trajectory ini untuk meningktakan ketermapilan dribbling pada pemain PS. UNDIKMA Mataram. Kemampuan para pemain PS. UNDIKMA Mataram bervariasi antara satu dengan yang lainnya, karna para pemain ada yang menonjol 
dari segi kecepatan saat melakukan dribbling. Akan tetapi sebagian besar para pemain sudah mempunyai teknik dasar bermain sepakbola yang cukup baik. Sehingga hanya membutuhkan sedikit latiahan tambahan untuk meningkatkan kemampuan menggiring bola pada pemain PS. UNDIKMA Mataram. Berdasarkan latar belakang di atas, maka peneliti berkeinginan untuk melakukan penelitian tentang "Pengaruh Latihan Dribbling With A Curving Line Trajectory Terhadap Ksterampilan Dribbling Pemain Sepak Bola PS. UNDIKMA Mataram Tahun 2019"

\section{KAJIAN PUSTAKA}

\section{Latihan}

Menurut Sukadiyanto (2005) menerangkan bahwa pada prinsipnya latihan merupakan suatu proses perubahan ke arah yang lebih baik, yaitu untuk meningkatkan kualitas fisik kemampuan fungsional peralatan tubuh dan kualitas psikis anak latih.dan Menurut Bompa (1994) latihan adalah aktivitas olahraga yang sistematik dalam waktu yang lama, ditingkatkan secara progresif dan individual yang mengarah kepada ciri-ciri fungsi psikologis dan fisiologis manusia untuk mencapai sasaran yang ditentukan.Istilah pelatihan berasal dari kata dalam Bahasa inggris yang dapat mengandung beberapa makna practice, exercises, dan training. Pengertian latihan berasal dari practice adalah aktivitas untuk mengingkatkan keterampilan (kemahiran) berolahraga dengan menggunakan berbagai peralatan sesuai dengan tujuan dan kebutuhan cabang olahraganya. Artinya, selama dalam kegiatan proses berlatih melatih agar dapat menguasai keterampilan gerak cabang olahrganya selalu dibantu dengan menggunakan berbagai peralatan pendukng, (Mylsidayu dan Kurniawan, 2015).

\section{Dribbling With A Curving Line Trajectory}

Model latihan Dribbling With A Curving Line Trajectory merupakan salah satu latihan menggiring bola melalui lintasan garis lengkung dengan menggunakan berbagai bagian-bagian kaki untuk menggiring bola dan menggunakan kun untuk dilalui.Model latihan dribbling with a curving line trajectory merupakan latihan menggiring bola melalui lintasan garis lengkung dengan menggunakan kun untuk dilaluinya. (Rius, 2001:46)Model latihan dribble individual with cone merupakan suatu model latihan menggiring bola, dimana bola digiring melewati kun dengan gaya yang acak dalam lapangan yang luas Joseph A. Luxbacher (1997:57) dalam melakukan dribble dengan gaya yang acak dalam lapangan yang luas, menggunakan berbagai bagian kaki untuk menggiring bola. Terapkan perubahan arah dan kecepatan dalam pola dribble anda. Dalam bentuk latihan dribble individual with cone pemain dituntut untuk merubah arah secepat mungkin dengan memotong bola menggunakan pununggung kaki (instep), kemudian bergerak mengitari kun dengan mendorong bola menggunakan kaki bagian luar (outside-ofthe foot).Langkah-langkah melakukan latihan dribbling with a curving line trajectory adalah:

a) Membuat rintangan berbentuk persegi yang berukuran $5 \times 5$ meter.

b) Letakkan 4 buah kun untuk rintangannya dengan jarak masing-masing kun 5 meter.

c) Masing-masing sampel diberikan 1 buah bola.

d) Sampel pada barisan pertama bersiap untuk melakukan dribble disamping kun atau garis start dengan bola dalam penguasaan kakinya.

e) Pada aba-aba"ya" sampel mulai menggiring bola dengan perlahan-lahan, meningkatkan kecepatan dribble dan secara bersamaan tanpa saling bertabrakan antara pemain satu dengan pemain lainnya, mengitari kun menggunakan kaki bagian dalam dan kaki bagian luar (instep dan outside-of the foot) sampai rintangan selesai kemudian sampel berhenti dan kembali ke barisan paling belakang menunggu giliran berikutnya.

f) Dilanjutkan oleh sampel pada brisan kedua dengan cara yang sama dan demikian juga dilakukan oleh sampel ketiga sampai dengan sampel yang terakhir, seterusnya kembali sampai ke giliran sampel pada barisan pertama. 
g) Setiap sampel diberikan waktu 30 detik dalam satu kali perlakuan.

Untuk lebih jelasnya dapat dilihat pada gambar berikut ini:

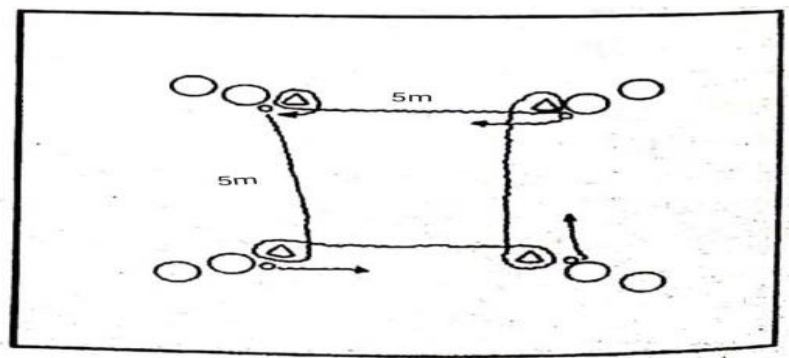

Gambar 1.1 Model latihan dribbling with a curving line trajectory (Rius, 2001:46).

\section{Keterampilan}

Keterampilan manusia meliputi beberapa bentuk, ada yang menekankan pada kontrol dan koordinasi kelompok otot-otot besar, secara relatif menunjukkan kekuatannya seperti sepakbola atau berguling, ada yang sekelompok otot kecil yang harus tepat bekerja seperti mengetik dan memperbaiki jam. Secara umum teks ini memusatkan pada keluasan perilaku keterampilan sebab untuk memahami ciri-ciri yang mendasari penampilan keterampilan dari penggabungan keterampilan, terutama menErapkannya pada olahraga, permainan, tari dan aktivitas serupa sebagai bagian secara luas dari keterampilan manusia. Ketika pemain melakukan latihan dribbling with a curving line trajectory, peneliti mengamati gerakan dribbling sejak melewati kun pertama sampel menerapkan berbagai macam gaya dalam dribbling yang dilanjutkan melewati kun berikutnya. Tanpa merasa terbebani dengan rute atau lintasan kun yang akan dilewatinya secara spontan sampel menimbulkan kreasi gerakan dribble yang dilakukan dengan cepat dan berulang-ulang. Berdasarkan mekanisme gerakan dribble yang dilakukan pemain, maka bentuk latihan dribbling with a curving line trajectory lebih memaksimalkan kecepatan dribble jika diterapkan dalam latihan teknik dribble.

\section{Dribbling}

Kemampuan dribbling adalah salah satu upanya menggiring bola dari satu titik ke titik yang lain di dalam lapangan dengan menggunakan berbagai bagian-bagian kaki untuk menggiring bola. Menggiring bola adalah salah satu teknik bermain sepakbola yang sangat mendasar dan mutlak harus dikuasai oleh pemain sepakbola. Menggiring bola adalah salah satu kemampuan untuk membawa bola ke arah yang diinginkan. Menggiring bola juga untuk menyelamatkan bola apabila tidak ada kemungkinan untuk di passing dengan cara membebaskan diri dari tekanan lawan.. Robert Koger (2007:51) menyatakan bahwa: Menggiring bola adalah metode menggerakkan bola dari satu titik ke titik lain di lapangan dengan menggunakan kaki, bola harus selalu dekat dengan kaki agar mudah dikontrol".

\section{Sepakbola}

Sepak bola adalah permainan beregu yang dimainkan oleh dua regu, yaitu masingmasing regunya terdiri atas sebelas pemain termasuk seorang penjaga gawang. Permainan sepak bola dilakukan dengan seluruh anggota badan kecuali dengan kedua lengan tangan (Sukatamsi, 1997: 28). Permainan olahraga sepak bola merupakan cabang olahraga beregu. Untuk memenangkan pertandingan setiap regu berusaha memasukkan bola ke gawang lawan sebanyak-banyaknya dan berusaha mempertahankan gawangnya agar tidak dapat dimasukkan oleh tim lawan. Pemain sepak bola harus dapat memiliki bekal yang baik agar dapat bermain dengan baik. Penguasaan teknik dan taktik serta didukung dengan keadaan fisik bisa membuat pemain sepak bola dapat bermain secara maksimal.Tantangan fisik dan mental yang dihadapi pemain benar-benar luar biasa. Keberhasilan tim dan keberhasilan individu dalam bermain sepak bola akhirnya tergantung sepenuhnya pada kemampuan pemain dalam menghadapi tantangan dalam pertandingan sepak bola. Kemampuan demikian perlu dikembangkan melalui latihan.

\section{METODE PENELITIAN}

\section{Rancangan kegiatan}

Rancangan penelitian adalah keseluruhan proses pemikiran dan penentuan 
matang tentang hal-hal yang dilakukan. Ia merupakan landasan berpijak, serta dapat dijadikan dasar penilaian baik oleh peneliti sendiri maupun orang lain terhadap kegiatan penelitian. Dengan demikian rancangan penelitian bertujuan untuk memberi pertanggung jawaban terhadap semua langkah yang akan diambil. (Margono, 2005:100).Adapun jenis penelitian dalam penelitian ini adalah penelitian eksperimen, dimana penelitian eksperimen merupakan metode penelitian yang digunakan untuk mencari pengaruh treatment (perlakuan) tertentu. (Sugiyono, 2013:11). Dalam rancangan penelitian ini menggunakan The Static Group Pretest-Postest Design. Dalam desain ini terdapat dua kelompok yang dipilih dengan dua perlakuan yang berbeda tanpa adanya kelompok kontrol dan sampel ditentukan melalui pemilihan acak atau undian. (Sumadinata, 2015).

\section{Ruang lingkup}

Ruang lingkup penelitian tentang penelitian ekperimen Pengaruh Latihan Dribbling With A Curving Line Trajectory Untuk Meningkatkan Keterampilan Dribbling Pemain Sepak Bola PS. UNDIKAM Mataram Tahun 2019. jadi objek penelitian adalah orang tua siswa tersebut. Mengingat luasnya Permasalahan dan dengan pertimbangan segala keterbatasan maka peneliti membatasi pada salah satu permasalahan yaitu

a) Subjek penelitian

Subjek penelitian adalah Dribling sepakbola Ps UNDIKMA Mataram .

b) Objek Penelitian

Sampel adalah bagian dari jumlah dan karekteristik yang di miliki oleh populasi tersebut (Sugiyono, 2013:118). Bila populasi besar dan peniliti tidak mungkin mempelajari semua yang ada pada populasi, misalnya karena keterbatasan dana, tenaga dan waktu, maka peneliti dapat menggunakan sampel yang di ambil dari populasi itu. Apa yang di pelajari dari sampel itu, kesimpulannya akan dapat di berlakukan untuk populasi. Untuk itu sampel yang di ambil dari populasi harus betul-betul representative (mewakili). Tehnik pengambilan sampel menggunakan tehnik studi populasi. Dalam penelitian ini peneliti menggunakan seluruh populasi untuk di jadikan sampel penelitian yaitu seluruh pemain PS. UNDIKMA Mataram Tahun 2019 yang berjumlah 11 orang, sehingga penelitian ini merupakan penelitian studi populasi.

\section{Bahan dan alat utama}

Instrumen untuk penelitian ini berbentuk Menurut Arikunto, (2010:192) Dalam buku metode penelitian dijelaskan bahwa insrtumen adalah suatu alat pada waktu penelitian menggunakan suatu metode. Untuk memperoleh data di perlukan alat pengukuran, yang di maksud dengan instrumen adalah alat pada waktu penelitian dengan menggunakan suatu metode.(Suharsimin, 2013: 192). Dengan kata lain metode tidak dapat memenuhi fungsinya dengan efektif apabila instrumen yang menjadi alat dari metode itu tidak falid. Di samping alat pengukuran harus di susun sedemikian rupa agar data secara tepat merekam data yang dimaksud. Dalam penelitian ini peneliti menggunakan instrumen tesnya sebagai berikut: menggiring bola.

Skor:Waktu yang ditempuh oleh sampel dari mulai aba-aba "ya" sampai ia melewati garis finish.

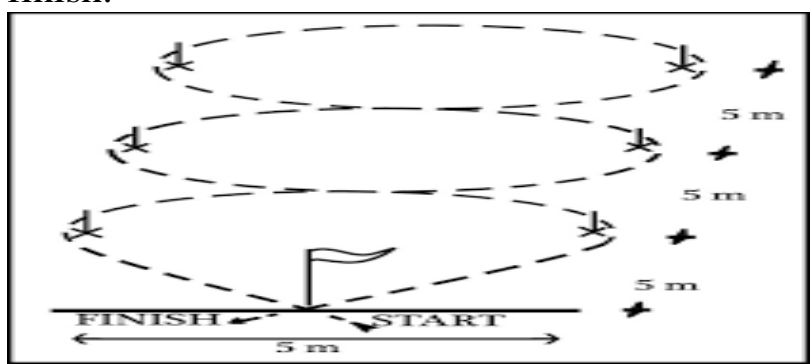

Gambar 1.2 Tes Menggiring Bola (Nurhasan, 2001:161)

\section{Cara pelaksanaan dan penilaian}

1) Pada Aba-Aba"Siap", Sampel berdiri disamping garis start dengan bola dalam penguasaan kakinya.

2) Pada aba-aba "Ya", sampel mulai menggiring melewati rintangan pertama 
dan menuju rintangan berikutnya sesuai dengan arah yang telah ditetapkan sampai intruksi berhenti.

3) Bila salah arah menggiring bola sampel harus memperbaikinya tanpa menggunakan anggota badan selain kaki di tempat kesalahan terjadi dan selama itu pula stopwatch tetap berjalan.

4) Bola digiring menggunakan kaki bagian dalam dan kaki bagian luar (instep dan outside-of the foot) secara bergantian atau paling tidak salah satu kaki pernah nyentuh bola satu kali sentuhan.

\section{Gerakan tersebut dinyatakan gagal:}

1) Sampel menggiring bola hanya dengan menggunakan satu kaki saja.

2) Sampel menggiring bola tidak sesuai dengan arah panah.

3) Sampel menggunakan anggota badan lainya selain kaki, untuk menggiring bola.

Alat yang digunnakan pada penelitian yaitu:

1) Bola

2) Stopwatch.

3) Kerucut atau kun.

4) Meteran.

5) Peluit.

\section{Tempat}

\begin{abstract}
Penelitian ini dilaksanakan di lapangan Rembige Mataram, Waktu Penelitian yang dijelaskan dan difokuskan pada pengambilan data yaitu dilaksanakan pada tanggal 22 September s/d 9 desember 2019.
\end{abstract}

\section{Teknik penumpulan data}

Sugiyono ( 2013: 308) teknik mengumpulan data merupakan langkah yang paling utama dalam penelitian, karena tujuan utama dari penelitian adalah mendapatkan data. Tanpa mengetahui teknik pengumpulan data, maka peneliti tidak akan mendapatkan data yang memenuhi standar data yang ditetepkan. Sedangkan menurut Arikunto (2006: 129) sumber data adalah subjek dari mana data dapat diperoleh. Dalam penelitian ini metode yang digunakan untuk memperoleh data tersebut adalah metode dokumentasi, dan metode tes perbuatan.

\section{a) Teknik Observasi}

Observasi merupakan suatu metode pengumpulan data, observasi diartikan sebagai suatu proses yang kompleks, suatu proses yang tersusun dari berbagai proses biologis dan psikologis (Sugiyono, 2013:203). Ahli lain berpendapat bahwa, observasi adalah melakukan pengamatan secara langsung ke objek penelitian untuk melihat dari dekat kegiatan yang dilakukan (Ridwan, 2010:76).

\section{b) Metode Tes Perbuatan}

Dalam buku evaluasi pendidikan dijelaskan bahwa: "Tes adalah alat pengumpulan data yang berbentuk suruhan yang harus dilaksanakan oleh obyek penelitian" Tes adalah suatu cara untuk mengadakan penelitian terhadap suatu subjek atau obyek tertentu untuk mendapatkan data secara cepat dan tepat (Arikunto, 2006:44). Dalam penelitian ini, menggunakan tes menggiring bola untuk mengukur kemampuan dribbling sepakbola pada Pemain Sepak Bola PS. UNDIKMA Mataram Tahun 2019.

c) Teknik Dokumentasi

Teknik dokumentasi dalam penelitian ini digunakan untuk memperoleh data melalui catatan yang bersifat kuantitatif, data ini dapat bersifat pribadi atau pengalaman yang ditulis oleh subjek, data yang diperoleh dari pengamatan langsung yang diperkuat oleh peneliti dengan menggunakan teknik dokumentasi dalam mengumpulkan data. Dokumentasi diperlukan dalam penelitian kuantitatif, karena menghasilkan deskriptif yang berharga dan digunakan untuk mengolah segi-segi subjektif dan hasil yang di analisa secara induktif.

\section{Difinisi operasional variable}

\section{Latihan}

Tangkudung, (2012) Pengertian latihan yang berasal dari kata exercise 
adalah perangkat utama dalam proses latihan harian untuk meningkatkan kualitas fungsi organ tubuh manusia sehingga mempermudah atletdalam peyempurnaan gerakan. Sususnan materi latihan dalam satu kali tatap muka berisi: (1) pembukaan/pengantar, (2) pemanasan (warming up), (3) latihan Inti, (4) latihan tambahan, (suplemen), dan (5) cooling down/penutup.

\section{Dribbling With A Curving Line Trajectory}

Model latihan Dribbling With A

Curving Line Trajectory merupakan salah satu latihan menggiring bola melalui lintasan garis lengkung dengan menggunakan berbagai bagian-bagian kaki untuk menggiring bola dan menggunakan kun untuk dilalui.Model latihan dribbling with a curving line trajectory merupakan latihan menggiring bola melalui lintasan garis lengkung dengan menggunakan kun untuk dilaluinya. (Rius, 2001:46)

\section{Keterampilan}

Widiastuti, (2011). menjelaskan gerak keterampilan adalah: Gerak yang mengikuti pola atau bentuk tertentu yang memerlukan koordinasi dan kontrol sebagian atau seluruh tubuh yang bisa dilakukan melalui proses belajar.

\section{Dribbling}

Menurut A. Sarumpaet dkk, (1992:24) mengatakan menggiring bola merupakan teknik dalam usaha memindahkan bola dari suatu daerah permainan kedaerah yang lain pada saat permainan berlangsung.

\section{Sepakbola}

Sepak bola adalah permainan beregu yang dimainkan oleh dua regu, yaitu masing-masing regunya terdiri atas sebelas pemain termasuk seorang penjaga gawang. Permainan sepak bola dilakukan dengan seluruh anggota badan kecuali dengan kedua lengan tangan (Sukatamsi, 1997: 28).

\section{Teknik analisa data}

Untuk memperoleh satu kesimpulan masalah yang di teliti, maka analisis data merupakan satu langkah penting dalam penelitian. Sesuai dengan rumusan masalah dan tujuan penelitiannya maka analisis data yang digunakan dalam penelitian ini adalah $t$-test dengan rumus: Maka digunakan analisis statistik dengan rumus sebagai berikut (Sugiyono, 2009:74).

$$
t=\frac{\sum D}{\sqrt{\frac{N \cdot \sum D^{2}-\left(\sum D\right)^{2}}{(N-1)}}}
$$

Keterangan:

$\mathrm{D}=$ Perbedaan setiap pasangan skor (post test-pre test)

$\mathrm{N}=$ Jumlah sampel yang digunakan

Adapun langkah-langkah menganalsis data adalah sebagai berikut:

1. Merumuskan hipotisis

2. Menyusun table kerja (table persiapan)

3. Mendistribusikan data kedalam rumus

4. Menguji nilai T

5. Menarik kesimpulan

$$
\text { Peningkatannya }=\frac{M d}{\text { Mpre }} \times 100
$$

\section{HASIL DAN PEMBAHASA}

Untuk pengolahan data dari hasil dari Tes Menggiring Bola (Nurhasan, 2001:161) kepada PS. IKIP Mataram Tahun 2019 tadalah sebagai berikut: Tabel 1.1 : Hasil Data Pre-test dan Post-test menggiring Bola kelompok Dribbling With A Curving Line Line Trajectory Terhadap Kemampuan Dribbling Pemain Sepak Bola PS. UNDIKMA Mataram Tahun 2019 


\begin{tabular}{|c|l|c|c|c|c|} 
No & \multicolumn{1}{|c|}{ Nama } & XI & XII & $\begin{array}{c}\text { D } \\
\text { XII- }\end{array}$ & $D^{2}$ \\
\hline 1 & Gokil & 11.8 & 11.62 & -0.18 & 0.0324 \\
\hline 2 & Putu Oka & 11.73 & 11.6 & -0.13 & 0.0169 \\
\hline 3 & Rijal Jayadin & 10.4 & 10 & -0.4 & 0.16 \\
\hline 4 & Hamzanwadi & 10.4 & 10.02 & -0.38 & 0.1444 \\
\hline 5 & Azhar Subagya & 10.4 & 10 & -0.4 & 0.16 \\
\hline 6 & Abdul Basid & 10.7 & 10.1 & -0.6 & 0.36 \\
\hline 7 & Feby Resnanto & 11.65 & 11.15 & -0.5 & 0.25 \\
\hline 8 & Asrori & 11.42 & 11.04 & -0.38 & 0.1444 \\
\hline 9 & Fawas & 10.51 & 10.07 & -0.44 & 0.1936 \\
\hline 10 & Marta Suama & 9.64 & 9.12 & -0.52 & 0.2704 \\
\hline 11 & Rian & 9.72 & 9.24 & -0.48 & 0.2304 \\
\hline & & $\mathbf{1 1 8 . 3 7}$ & $\mathbf{1 1 3 . 9 6}$ & $\mathbf{- 4 . 4 1}$ & $\mathbf{1 . 9 6 2 5}$ \\
\hline
\end{tabular}

Keterangan:

$\mathrm{XI}=($ Pre-test $)$ menggiring bola

$\mathrm{XII}=($ Post-test $)$ menggiring bola

$\mathrm{D}=\mathrm{XII}-\mathrm{XI}$

$\mathrm{N}=11$

Pada langkah ini data hasil tes Pre-test dan Post-test menggiring Bola kelompok Dribbling With A Curving Line Line Trajectory yang sudah tercantum dalam tabel di atas kemudian dimasukkan kedalam rumus "t-test" sebagai berikut :

$$
\begin{gathered}
t=\frac{\sum D}{\sqrt{\frac{N \cdot \sum D^{2}-\left(\sum D\right)^{2}}{(N-1)}}} \\
t=\frac{-4.41}{\sqrt{\frac{11.1,9625-19,44}{(11-1)}}} \\
t=\frac{-4.41}{\sqrt{\frac{12,93}{10}}} \\
t=\frac{-4.41}{\sqrt{0.359}} \\
t=\frac{-4.41}{0,599} \\
t=7,362
\end{gathered}
$$

Berdasarkan hasil pengolahan dan analisis data terhadap hasil penelitian dengan menggunakan analisis $t$-test terhadap hipotesis yang di ajukan dalam penelitian ini ternyata teruji kebenarannya. Temuan-temuan dalam penelitian ini seperti yang dikemukakan di atas merupakan hasil analisis secara statistik yang akan peneliti kaji lebih lanjut (Dribbling With $A$
Curving Line Trajectory) X1 sebesar Nilai $t_{\text {hitung }}$ 7,358. dan nilai $t_{\text {hitung }}$ secara simultan antara $Y$ dan X1 menarik kesimpulan analisis tabel pada taraf signifikan 5\% dengan jumlah sampel ( $\mathrm{n}-$ 1 ) yaitu $22-1=21$ sebesar 1.812. Dari hasil penelitian menunjukkan (Dribbling With A Curving Line Trajectory Trajectory) X1 sebesar Nilai $t_{\text {hitung }} 7,358$. secara simultan antara Y dan $\mathrm{X} 1$ menarik kesimpulan analisis tabel pada taraf signifikan $5 \%$ dengan jumlah sampel $(\mathrm{n}-1)$ yaitu $11-1=21$ sebesar 1.812, ada Pengaruh Pengaruh Latihan Dribbling With A Curving Line Trajectory Terhadap Keterampilan Dribbling Pemain Sepak Bola PS. UNDIKMA Mataram Tahun 2019

\section{KESIMPULAN}

Jadi dari hasil penelitian X1 (Dribbling With A Curving Line Trajectory), X2 Latihan Dribbling With Zig-Zag Trajectory dengan Y1 diperoleh $t_{\text {hitung }}$ jauh lebih besar dari $t_{\text {tabel }}$, hal ini menunjukkan bahwa hipotesis "Ha" (diterima) maka penelitian ini signifikan. menarik kesimpulan analisis tabel pada taraf signifikan $5 \%$ dengan jumlah sampel $(n-1)$ yaitu $11-1=$ 10 sebesar 1.812, . Maka dapat disimpulkan bahwa Pengaruh Latihan Dribbling With A Curving Line Trajectory Terhadap Keterampilan Dribbling Pemain Sepak Bola PS. UNDIKMA Mataram Tahun 2019, Nilai $t_{\text {hitung }}>$ iel $(7,362>1.812)$.

\section{SARAN}

Berdasarkan pengamatan peneliti selama mengadakan penelitian dan dari hasil analisis data, maka peneliti mengajukan saran-saran sebagai berikut:

1. Kepada Pemain

Bagi para pemain atau anggota Pemain Sepak Bola PS. UNDIKMA Mataram Tahun 2019 hendaknya bersungguh-sungguh dalam melakukan latihan, terutama latihan teknik dasar sepakbola, dan kondisi fisik yaitu masalah menggiring bola guna mendapatkan keterampilan yang dibutuhkan.

2. Kepada pembina/pelatih

Kepada pembina/pelatih agar merperhatikan keterampilan yang dimiliki 
anak didik, kemudian berusaha untuk membina dan mengembangkan bakat yang dimiliki oleh anak didik dengan memberikan latihan-latihan yang terprogram.

3. Kepada Pemerintah Terkait

Kepada pemerintah terkait di kota Mataram agar lebih memperhatikan perkembangan atlit- atlit yang ada di daerah kota Mataram khususnya atlit sepak bola, kemudian memberikan dukungan serius berupa moril dan materil baik dari segi sarana dan prasarana yang di perlukan dalam olahraga sepak bola seperti lapangan sepak bola, kostum dll. Pada Pemain Sepak Bola PS. UNDIKMA Mataram Tahun 2019/

\section{REFRENSI}

Arikunto, Suharsimi. 2006. Penelitian Tindakan Kelas. Jakarta: Bumi Aksara. 2010. Prosedur Penelitian

Suatu Pendekatan Praktik. Jakarta: Rineka Cipta.

Bompa, Tudor O. 1994. Theiry and Methodologi of Training. lowa: Kendal/HuntPublishing Company

Glifford, Clive. 2007. Keterampilan Sepak Bola, Jakarta, PT. Citra Aji Parama.

http://download.portalgaruda.org/article.php?a rticle $=94909 \& \mathrm{val}=1226$

https://lib.unnes.ac.id/23328/1/6301411066.pdf

(www.quickness-drillss.com).

http://www.fitnessformen.co.id/article/2/2014/7

87-BerlatihSepertiPebasket- Profesional: 12 Februari 2014).

Hulfian, Lalu. 2014. Penelitian Dikjas. Selong: CV. Garuda Ilmu.

Harsono. 2004. Latihan Kondisi Fisik Edisi Revisi Coaching dan Aspek-Aspek Psikologi Dalam Coaching.Bandung: CV. Tambak Kusuma.

IKIP MATARAM. 2011. Pedoman Pembimbingan dan Penulisan Karya ilmiah.IKIP Mataram.

Luxbacher, Joseph A. 1997. SEPAKBOLA: Langkah-langkah Menuju Sukses (Soccer:Steps to Success). Alih Bahasa.
Agusta Wibawa (ed.2) Jakarta: PT.RajaGravindoPersada. 2012. Sepakbola (Edisi

kedua). Jakarta: PT. Raja grafindo Persada.

Morgono. 2005. Metodelogi Penelitian. Jakarta: Aneka Cipta, Fakultas Ilmu Keolahragaan. Universitas Negeri Surabaya.

Mielke, Danny. 2007. Dasar-dasar Sepakbola. (Soccer Fundamentals). Alih Bahasa. Eko Wahyu Setiawan, S.S. Pakar Raya, PT. Intan Sejati.

Nurhasan. 2001. Tes Menggiring Bola.

Rius, Jose Segura. 2001. Teaching the Skill of Soccer, Reedswain Publising.

Sajoto, M. 1988. Pembinaan Kondisi Fisik dalam Olahraga, Jakarta, DepartemenPendidikandanKebudayaan.

Sarumpaet, Aip. 1992. Permainan Besar, Jakarta, Departemen Pendidikan dan Kebudayaan.

Sucipto. 2000. Sepak Bola, Direktorat Jendral Pendidikan Dasar Dan Menengah, Departeman Pendidikan Dan Kebudayaan.

Sugiyono. 2009. Metode Penelitian Pendidikan

(Pendekatan Kuantitatif, Kualitatif, dan $R \& D)$. Bandung: Alfabeta.

2013. Hipotesis Penelitian.

(Metodologi Penelitian Kuantitatif, Kulitatif dan R\&D). Bandung: Alfabeta.

Sukadiyanto. 2005. Pengantar Teori dan Metodologi Melatih Fisik. Bandung: Lubuk Agung.

Sukmadinata, Nana Syaodih. 2015. Metodologi Pelatihan Pendidikan. Bandung: Remaja Rosdakarya.

Dedy Sumiyarono. 2006. Teori dan Metodologi Melatih Fisik Bolabasket. Teori dan Metodologi Melatih Fisik Bolabasket. Yogyakarta: FIK UNY.

Tangkudung, James. 2012. Kepelatihan Olahraga" Pembinaan Prestasi 
Olahraga" Edisi II. Jakarta: Cerdas Jaya.

Widiastuti. 2015. Tes dan Pengukuran Olahraga, Jakarta: PT Raja Grafindo Persada. 